\title{
Coping, fostering resilience, and driving care innovation for autistic people and their families during the COVID-19 pandemic and beyond
}

\author{
Stephanie H. Ameis ${ }^{1,2,3^{*}+}$, Meng-Chuan Lai ${ }^{1,2,3,4,5^{*}+}$ (D), Benoit H. Mulsant ${ }^{1,3}$ and Peter Szatmari ${ }^{1,2,3}$
}

\begin{abstract}
The new coronavirus disease (COVID-19) pandemic is changing how society operates. Environmental changes, disrupted routines, and reduced access to services and social networks will have a unique impact on autistic individuals and their families and will contribute to significant deterioration in some. Access to support is crucial to address vulnerability factors, guide adjustments in home environments, and apply mitigation strategies to improve coping. The current crisis highlights that our regular care systems are not sufficient to meet the needs of the autism communities. In many parts of the world, people have shifted to online school and increased use of remote delivery of healthcare and autism supports. Access to these services needs to be increased to mitigate the negative impact of COVID-19 and future epidemics/pandemics. The rapid expansion in the use of telehealth platforms can have a positive impact on both care and research. It can help to address key priorities for the autism communities including long waitlists for assessment and care, access to services in remote locations, and restricted hours of service. However, system-level changes are urgently needed to ensure equitable access and flexible care models, especially for families and individuals who are socioeconomically disadvantaged. COVID-19 mandates the use of technology to support a broader range of care options and better meet the diverse needs of autistic people and their families. It behooves us to use this crisis as an opportunity to foster resilience not only for a given individual or their family, but also the system: to drive enduring and autism-friendly changes in healthcare, social systems, and the broader socio-ecological contexts.
\end{abstract}

Keywords: Autism, SARS-CoV-2 virus, COVID-19, Pandemic, Resilience, Telehealth, Health services, Equity

Autism spectrum disorder (ASD) is a relatively common neurodevelopmental condition [1] characterized by longstanding social communication challenges and restricted, repetitive, and inflexible patterns of behavior, interests, and activities (RRBI). Intensity of presentation, verbal and cognitive abilities, and adaptive functioning vary

\footnotetext{
*Correspondence: Stephanie.Ameis@camh.ca; mengchuan.lai@utoronto.ca Stephanie H. Ameis and Meng-Chuan Lai equally contributed to this study. ${ }^{1}$ Centre for Addiction and Mental Health, 80 Workman Way, Toronto, ON M6J $1 \mathrm{H} 4$, Canada

Full list of author information is available at the end of the article
}

significantly across individuals on the autism spectrum and even within an individual over time. Autistic individuals (we acknowledge that some identify as, or prefer the terms "individuals with autism" or "individuals with ASD") also experience high rates of co-occurring physical and mental health conditions (e.g., gastrointestinal and sleep problems, ADHD, anxiety, and depression) across the lifespan $[2,3]$, contributing to complexity and heterogeneity of presentation. Although all autistic individuals and their families require some forms of support [4], care needs vary considerably across individuals and 
across the lifespan. The new coronavirus disease (COVID-19) pandemic has changed how our local community and global society operate, impacting autistic individuals and their families, as well as autism clinical services and research progress [5]. An early analysis of globally federated electronic medical record data (through May 14, 2020) shows that individuals with intellectual and developmental disabilities (IDD, including autism) have higher prevalence of specific physical comorbidities associated with poorer COVID-19 outcomes. Furthermore, among younger people ( $\leq 17$ years), those with IDD are more likely to be infected and experience higher fatality rate than those without IDD [6]. Within days of the World Health Organization declaring the pandemic, physical distancing measures were implemented, leading to the closure of schools and businesses, transition to work-from-home when possible, massive job loss, and economic uncertainty. With the aim of protecting physical health, such societal mitigation measures have inadvertently impacted the mental health and well-being of autistic individuals and their families, resulting in high stress, increased mental health challenges, and disrupted services and supports (e.g., see USbased survey report: https://sparkforautism.org/discover article/covid-19-impact-asd/ \& https://sparkforautism. org/discover_article/covid-19-and-its-impact-on-autisticadults/). Early data from Italy have highlighted the negative impact to families with autistic children, including daily challenges managing structured activities and free times, and increased behavior regulation difficulties for the child (especially when behavioral challenges predate COVID-19) [7]. Turkish parents of autistic children also report higher levels of anxiety and lower feelings of dispositional hope and psychological well-being compared to parents of neurotypical children [8].

Autistic individuals and their families can be particularly impacted by the COVID-19 pandemic and the sequelae [9-11], especially those with intellectual disability or with high support needs $[6,12,13]$. For example, only $25 \%$ of autistic adults live in their own households [14], and many autistic adults with high support needs live in congregate care settings (e.g., long-term care facilities or group homes). The characteristics of these settings (i.e., shared bedrooms, bathrooms, and common space) and of their residents (e.g., with medical comorbidities, cognitive impairment, or dysregulated behavior) may impede traditional measures to prevent the spread of the virus (e.g., physical distancing and frequent handwashing) $[15,16]$. In addition, staff working across facilities can also accelerate the spread. Whether autistic individuals' health and developmental vulnerability interacts with the pathophysiology of, and host responses to, the SARS-CoV-2 virus is not yet known, neither is its long-term developmental impact on the body and the brain [17]. The current pandemic is likely to have prolonged course and impact [18]. Similar epidemics and pandemics are also possible in the future. Therefore, it is essential to monitor the short-term and long-term challenges for autistic people and their families [10], reflect on the unique challenges that autistic individuals and their families are facing during the pandemic, and consider opportunities to support coping moving forward.

\section{The impact of environment changes and disrupted routines during the COVID-19 pandemic}

The person-environment fit is crucial to the functioning and well-being of autistic individuals [4], as are parentchild interactions $[19,20]$. The pandemic is changing several factors closely associated with the personenvironment fit. These factors include balancing autistic individuals' needs for routine and environmental predictability versus the unpredictability associated with the pandemic; family members' understanding of autistic individuals' social and sensory needs versus autistic individuals' understanding of family situation and family members' experiences; autistic individuals' learning or working styles versus available opportunities at this time; and the living environment or activity schedules among family members. Strong needs for sameness and adherence to routines are core features of autism. They have been linked to the high rates of anxiety and depression experienced by autistic individuals [21]. Changes to everyday routines and restrictions to regular service disrupt a number of domains (e.g., physical health, mental health, and familial factors). For example, reduced access to specific foods will impact autistic individuals with selective eating [22], potentially leading to reduced food intake, poorer nutrition, or worsening elimination problems and constipation. Restricted access to regular programming, preferred activities and places contributes to lower physical activity, which is already a concern among autistic individuals, as are higher rates of obesity [23]. Home confinement also may lead to more time spent pursuing special interests. Although motivation for special interests is linked to well-being and satisfaction in autistic individuals, very high intensity engagement has detrimental effects on these domains [24]. During this pandemic, it is particularly challenging to regulate time spent on screens, which is already increased in autistic children [25]. All these factors may contribute to the exacerbation of problematic RRBIs [26], sleep problems [27], and aggression (ranging from verbal to physical) with high rates of direction towards caregivers [28]. We expect the pandemic to particularly affect autistic individuals with more behavioral difficulties, who already (i.e., prior to COVID-19 pandemic) experience more dysregulation of sleep, attention, anxiety, and depressive 
symptoms and more often take psychotropic medications [29]. Thus, to mitigate the effects of the pandemic on these at-risk autistic individuals will require complex physical and mental healthcare, including psychosocial and behavioral supports for both the individual [29] and their caregivers, who are also expected to experience elevated stress and anxiety [30].

Because of the risks associated with living in congregate settings discussed above, some autistic individuals have moved back to living with their family members. Others may no longer be able to visit their family due to distancing measures. All these environmental modifications may change sensory input (e.g., due to louder or different noise at home) and increase stress and anxiety among autistic individuals and their families. However, these challenges can be mitigated if the personenvironment fit at home is comfortable. For instance, exposure to environments that cause social overload or sensory discomfort may be lowered with the judicious implementation of physical distancing measures necessitated by the pandemic. With gradual reopening of schools and businesses occurring after the first wave of the pandemic across many parts of the world, there is the potential that precautions will be tightened again to reduce virus spread and burden on medical systems with subsequent waves. The need to transition back and forth will be particularly difficult for autistic children and adults. This reality means that our care systems need to remain open, accessible, and flexible in response to the evolving crisis.

\section{The impact of school closure, shift to online schooling, and physical distancing during the COVID-19 pandemic}

Schools often provide opportunities for interventions including specialized education, mental health care [31], and social interaction; they are critical for regulation of behaviors. On the other hand, school can also be a highly challenging setting for some autistic individuals due to academic difficulties, co-occurring ADHD or anxiety [2], and high risk of school and cyber-bullying from peers [32, 33]. All of these factors contribute to trauma, depression, anxiety, and suicidality [32, 34]. Thus, closure of schools (and work environments for adults) may result in reduced stress in some autistic individuals and increased stress in others [9]. When the personenvironment fit is poor at home, school can be an outlet for young autistic individuals and their only option for social interaction. For autistic youth and adults, social interactions outside the school or work settings are already limited [35]. Therefore, physical distancing measures will further reduce access to this limited social support network (which is particularly crucial for adolescents and young adults [36]), potentially escalating mental health challenges (e.g., depression and suicidal ideation) [34] and have far-reaching consequences.

It is not yet known how the move toward online classrooms and distance learning during the pandemic will impact autistic individuals. For some, the freedom to be in their home environment with a self-paced schedule will have positive effects on learning outcomes and allow them to engage in RRBIs that are soothing and anxietyrelieving without negative social consequences. For others, a lack of one-on-one professional support in a structured, regulated environment, and away from distraction will be detrimental to learning. Making use of online platforms for education (or other services) will be the most difficult for those with high support needs, where communication and cognitive factors are critical barriers for engagement [37]. Provision of specialized education to support students with disabilities is legally mandated in many jurisdictions. However, access and quality are highly variable at the best of times (e.g., see [38] for a US example). This variability will increase with the added complexity of remote delivery. Online education also depends on digital access and caregiver availability in the home to support students, placing constraints on caregivers' work [39]. Thus, the pandemic will amplify academic challenges, socioeconomic disadvantages, and parental burden for many autistic children and their families.

\section{The impact of COVID-19 pandemic on autism diagnostic services}

The first wave of the COVID-19 pandemic and consequent mitigation measures (e.g., the closure of outpatient services) have resulted in challenges to autism diagnostic practices, which traditionally include inperson, interaction-based behavioral observation as a key component. In many jurisdictions, a formal autism diagnosis is required for a child to receive timely intervention and support. Thus, physical distancing measures may result in additional delays in formal diagnosis, compounding the current long waitlists for diagnostic assessments in many areas. These delays will deprive autistic children from timely support (e.g., early intervention, educational plan, and tailored medical care) that is needed to facilitate their development, health, and wellbeing. To mitigate this challenge, many diagnostic practices (particularly those for young children) have started to incorporate video-based naturalistic and caregivermediated behavioral observation (e.g., the Systematic Observation of Red Flags [40]), telehealth-based observation and interview [41], or are developing video-based observation and coding systems with remote administration of semi-structured activities by a parent or adult assessor based on the Autism Diagnostic Observation Schedule and the Brief Observation of Social 
Communication Change (e.g., the Brief Observation of Symptoms of Autism, BOSA, which is not yet validated as of July 9, 2020: https://www.semel.ucla.edu/autism/ video/brief-observation-symptoms-autism-bosa-training). Although some virtual assessments for autism have shown preliminary validity [41, 42], they are designed primarily for young children. Comparable assessments have not been validated in older children, youth, or adults. The diagnostic challenges highlighted by the pandemic are forcing our field to re-evaluate the "best practices" for diagnostic assessments for autism when considering accessibility, timeliness, quality, and comprehensiveness. They also highlight the need to decouple eligibility for services from a "confirmed" or "formal" autism diagnosis and consider providing intervention based on individual needs, developmental level, function, and symptoms.

\section{Mitigation strategies during the acute phase of disruption associated with the COVID-19 pandemic}

The pandemic creates ongoing and possibly long-lasting challenges. For autistic individuals and their families, short-term and medium-term mitigation strategies are as important as long-term prospects. We need to implement mitigation strategies quickly and learn from this experience to improve quick shifts to "new normal" care practices in the future. Maintenance of typical routines is impossible during the COVID-19 pandemic. However, the impact of changes in routines can be attenuated by jointly creating and implementing alternative routines, incorporating a regular bedtime and morning schedule, attention to sensory stimulation, adequate but limited exposure to media, regulated screen time, and attention to regular hygiene, food and water intake, daily exercise, and sleep. Maintaining social networks (even if the only viable option to do so is online) is critical for both autistic individuals and their families.

Ensuring access to adequate resources (e.g., education, healthcare, autism-specific support, financial support, parental support) should be a priority at this time, even if the majority of care resources must shift to virtual/remote delivery. Ongoing provision of care is critical for autistic people and their families to maintain stability and prevent deterioration of health and its associated burden on broader healthcare systems. Over the past two decades, psychotropic prescription rates have been increasing in children diagnosed with ASD [43, 44], with high rates of polypharmacy [44], and use of a variety of medication classes despite a lack of evidence [43, 44]. Tolerability of these psychotropic medications is a concern [45]. Although clinicians need to be mindful of the risk of over-prescribing medications that may contribute to poorer health in the long-term [46], clinicians will need to provide careful and timely intervention, targeting symptom reduction through pharmacological and non-pharmacological support to prevent crises and hospitalizations and facilitate environmental adjustments. As a result, it is crucial to maintain ongoing access to clinicians who provide care, support, and psychoeducation. They will need to address, in kind and compassionate ways, vulnerability factors, home environment, coping with current restrictions, implementation of mitigation strategies, and resources for dealing with stress. To date, our early experience has been mostly positive when providing mental health care remotely to verbal children, adolescents, and adults on the autism spectrum. Many autistic individuals are less stressed in their home environments without the need to travel to a clinic or hospital and manage sensory and social communication inputs in an unfamiliar and sometimes insensitive setting (e.g., inperson care interruptions due to hospital-wide overhead announcements). Some individuals seem to be able to communicate more effectively using telehealth platforms (via videoconference or telephone delivery), either verbally or with chat boxes. Clinicians also benefit from being able to see the home setting and to witness the interaction at home between parent and child or among household members including pets. Nevertheless, direct telehealth care may not work well for minimally verbal autistic individuals or those having difficulties adapting to virtual platforms. In these scenarios, support will need to be delivered in alternative ways (e.g., telehealth care delivered to and mediated by parents or family members).

A number of helpful COVID-19 online resources from local and global professional organizations have been collated to support care at this time (see Table 1). This growing list highlights the value of the internet in rapidly distributing practical information and offering timely mitigation strategies for autistic individuals and their families.

\section{Opportunities to foster resilience and improve care for autistic individuals and their families during and after the COVID-19 pandemic}

Despite the challenges of the current pandemic, our collective experiences with coping may cultivate resilience and reveal opportunities for creating more flexible and better care in the future. Resilience is a process of interactive adaptation that facilitates coping in the face of adversity linked with a person's neurological and psychological makeup [47], and, equally (if not more) importantly, the socio-ecological contexts [48]. Past research in families of autistic individuals has shown that resilience is associated with social support, coping style (e.g., problem-focused coping), cognitive appraisal, optimism, locus of control, self-efficacy, acceptance, sense of coherence, and positive family function [49, 50]. Autistic 
Table 1 Examples of COVID-19-related online resources

\begin{tabular}{|c|c|}
\hline \multicolumn{2}{|l|}{ General resources } \\
\hline World Health Organization & $\begin{array}{l}\text { https://www.who.int/campaigns/ } \\
\text { connecting-the-world-to-combat- } \\
\text { coronavirus/healthyathome }\end{array}$ \\
\hline World Psychiatric Association & $\begin{array}{l}\text { https://www.wpanet.org/covid-19- } \\
\text { resources }\end{array}$ \\
\hline COVIDwithKIDS & https://www.covidwithkids.org \\
\hline \multicolumn{2}{|l|}{ Autism-specific resources } \\
\hline $\begin{array}{l}\text { US Department of Health \& Human } \\
\text { Services, Interagency Autism } \\
\text { Coordinating Committee (IACC) }\end{array}$ & $\begin{array}{l}\text { https://iacc.hhs.gov/resources/ } \\
\text { coronavirus/ }\end{array}$ \\
\hline Autism Speaks & $\begin{array}{l}\text { https://www.autismspeaks.org/ } \\
\text { covid-19-information-and- } \\
\text { resources }\end{array}$ \\
\hline Autism Science Foundation & $\begin{array}{l}\text { https://autismsciencefoundation. } \\
\text { org/covid-19-resources/ }\end{array}$ \\
\hline Autism Society of America & $\begin{array}{l}\text { https://www.autism-society.org/ } \\
\text { covid-19/ }\end{array}$ \\
\hline UK National Autistic Society & $\begin{array}{l}\text { https://www.autism.org.uk/ } \\
\text { services/helplines/coronavirus.aspx }\end{array}$ \\
\hline $\begin{array}{l}\text { Canadian Autism Spectrum } \\
\text { Disorders Alliance }\end{array}$ & $\begin{array}{l}\text { https://www.casda.ca/resources/ } \\
\text { covid-19-navigation-guide/ }\end{array}$ \\
\hline Autism Spectrum Australia & $\begin{array}{l}\text { https://www.autismspectrum.org. } \\
\text { au/how-can-we-help/covid-19- } \\
\text { information }\end{array}$ \\
\hline $\begin{array}{l}\text { UCLA Center for Autism Research \& } \\
\text { Treatment }\end{array}$ & $\begin{array}{l}\text { https://www.semel.ucla.edu/ } \\
\text { autism/covid-19-resources }\end{array}$ \\
\hline $\begin{array}{l}\text { Health Care Access Research and } \\
\text { Developmental Disabilities Program } \\
\text { (H-CARDD) }\end{array}$ & $\begin{array}{l}\text { https://www.hcarddcovid.com/ } \\
\text { info }\end{array}$ \\
\hline
\end{tabular}

individuals demonstrate their resilience everyday through coping despite heightened stress and anxiety due to uncertainty and limited opportunities for inperson social interaction [9]. The knowledge about factors fostering resilience is critical to improve care and support for autistic individuals and their families [51] both during and after the pandemic. These factors should be considered in the context of the unique sets of socio-ecological and psychological stressors experienced by autistic people and their families during the pandemic, e.g., socio-interpersonal challenges during lockdown, accessibility to healthcare, and vulnerability to job loss and employment crisis [10].

Nonetheless, the disruption of an already fragile system of care during the pandemic could substantially worsen the mental health of autistic individuals and reduce access to care, and some of this worsening may not be reversible. Current system limitations compounded by the pandemic are particularly concerning in young children. The greatest gains of early interventions are made in autistic children who have begun to make progress by 3 years of age [52]. For those most disadvantaged by socio-cultural factors, access to basic services may not be available within an acceptable timeframe even at the best of times [53]. As autistic individuals grow up, their care needs change. Autistic youth and young adults have more emergency department visits, more primary and psychiatric care visits, and higher healthcare expenditures than other youth with special healthcare needs [54, 55]. Rates of complex mental health conditions (e.g., depression, schizophrenia spectrum disorders, and bipolar disorders) are more prevalent in autistic individuals than in the general population, and they increase with age [2]. Optimal care needs to be multidisciplinary, bringing autistic individuals, their families, and care providers together, to facilitate a shared decision-making process and personalized care delivered at the right time [4]. The COVID-19 pandemic has highlighted and magnified many existing and new problems in our service and care systems for autistic individuals and their families. Coping with the pandemic offers an opportunity for change and fostering the resilience of autistic individuals, families, service providers, and the overall care systems.

\section{Opportunities to use virtual platforms to deliver care for autistic individuals and their families}

Priorities enumerated by the autism communities include improved service delivery, development of personcentred interventions, improved education of family members to support and understand their autistic relatives, improved support for co-occurring mental health conditions and well-being, and research supporting adult transitions and lifespan issues [56] (also see: http://www. jla.nihr.ac.uk/priority-setting-partnerships/autism/top-1 0 -priorities/). Insufficient funding has impeded care delivery for autistic individuals within current healthcare service structures [57]. The rapid increase in the use of telehealth and virtual platforms for remote assessment and care delivery could have a positive impact on these key priorities for the autism communities. A growing evidence base supports the feasibility and effectiveness of tele-mental health care [31,58]. Virtual care can also address the issues of long waitlists, limited access in remote locations, restricted hours of service, and "noshow" rates [59]. Preliminary data have shown these benefits in autism diagnostic services for young children [60]. Virtual care could also reduce barriers to accessing care due to stigma [58].

\section{Technology to implement evidence-based interventions}

In young children with ASD, a shift toward using technological platforms could have a lasting impact on care delivery. Parent involvement in early intervention for young children can have positive long-term effects [4]; it predicts IQ into adulthood, achievement, and adaptive functioning [61]. Even low-cost, low-intensity 
parent-mediated interventions involving coaching parents around interacting with their young children with ASD can have immediate effects on social behavior and communication [62]. Increasing evidence suggests that caregivers could be trained remotely to deliver parentmediated interventions, and remote training can impact parent knowledge, intervention fidelity, and social behavior or communication skills of children [63, 64]. A rapid shift toward remote options to implement caregivermediated interventions could have an important impact. For example, in response to the COVID-19 pandemic, the Early Start Denver Model team has created online education modules to enhance caregiver-mediated early intervention (https://helpisinyourhands.org/course). Online resources for telehealth-based assessment and service delivery are also accumulating (e.g., https:// autismnavigator.com, https://triad.vkclearning.org). Additional telehealth-based support for early intervention (via caregivers) and targeted intervention for autistic children, youth, and adults should be developed and tested via remote clinical trials [65]. This would substantially enhance the accessibility to service and support even beyond the COVID-19 pandemic.

\section{Technology to facilitate coordinated multidisciplinary care}

Virtual platforms that do not require a team to be in the same place to deliver coordinated care can improve complex care delivery for autistic individuals and their families. As described by the American Academy of Pediatrics, the medical home concept can be implemented for a variety of general medical and psychiatric conditions; it includes a comprehensive centralized health record, culturally competent care, and interaction across schools and service providers to support families [66]. The model described for autistic individuals emphasizes care coordination and communication between families, clinical teams, community agencies, and education or employment settings [67].

\section{Technology to support a broader range of care options and early stages of stepped care}

The use of online platforms can change service delivery away from one-size-fits-all approaches [68]. It can ensure that more autistic individuals have access to care. It can support personalized and stepped care models (i.e., a system of delivering and monitoring support so that the most effective and least resource-intensive care is delivered first, with "stepping-up" to intensive services as required) where a variety of intervention approaches are available. Online platforms (e.g., https://autismnavigator.com) are particularly useful for large-scale access to earlier stages of care including psychoeducation, self-directed (or caregiverdirected), or minimally supported interventions (e.g., periodic check-ins to support self-directed interventions).
These platforms may also be useful to provide care for mild to moderate anxiety or depression [68].

\section{Ensuring equity and accessibility to improved virtual model of care should be a priority for health service systems}

The success of rapid expansion of telehealth for autistic individuals depends on a number of factors. They include flexible funding that provides equivalent remuneration for in-person and remote care [58]. Socioeconomic factors contributing to differential access also need to be considered. Currently, richer and better educated people are much more likely to access and benefit from digital care [69]. Some caregivers cannot access remote care while juggling the added workload imposed upon them during the pandemic. While we develop virtual care to improve access, we must be mindful that it could worsen care inequity and variability [31, 70]. We also need to develop alternative models to support autistic individuals and caregivers unable to access virtual care (e.g., distanced in-person visits). The COVID-19 pandemic emphasizes issues of inequity. Health professionals need to advocate for equalizing access and adopting a "digital health equity framework" [70].

\section{Every cloud has a silver lining}

US-based surveys of about 8,000 SPARK parents or guardians and 600 autistic adults in March-April 2020 reveal some positive experiences coping with the pandemic, despite high stress and disruption: positive use of time, extra family time and time to pursue hobbies, limiting social media and news, exploration of calming activities, slower pace for learning, and adaptation to virtual social connection, learning, and healthcare (see: https://sparkforautism. org/discover_article/covid-19-impact-asd/ \& https:// sparkforautism.org/discover_article/covid-19-and-its-impact-on-autistic-adults/); however, it is likely that the respondents of these surveys have better resources, and they may not be representative of the autism population at large. An Autistica live article indicates that global changes required by the pandemic can lead to better understanding and accommodation for autistic people in the medium and long-term, including more flexible and empathetic workplaces; improved access to resources, events, and therapeutic support that can be offered remotely; and embracing innovative and more diverse teaching and learning opportunities (https://www.autistica.org.uk/news/ world-after-coronavirus). More lessons will be learned and innovations developed in the coming months for autistic individuals and their families [5]. In the long-term, this pandemic could foster resilience not only for the autism communities and the stakeholders, but also for the professionals who provide care. The current crisis could serve as a turning point to change the health and social 
systems and the broader socio-ecological contexts to be more flexible, empathetic, and autism-friendly. Once the pandemic is resolved, useful new models of care can be maintained and generalized instead of reverting back to the business-as-usual pre-pandemic state. The pandemic is an opportunity for stress inoculation [51]: if we can make the COVID-19 experiences manageable, we are better prepared for other crises in the future.

\section{Abbreviations}

ADHD: Attention-deficit/hyperactivity disorder; ASD: Autism spectrum disorder; COVID-19: Coronavirus disease 2019; RRBI: Restricted, repetitive, and inflexible patterns of behavior, interests, and activities

\section{Acknowledgements}

The authors would like to thank the anonymous reviewers for their constructive suggestions to enrich the content and discussion of this commentary.

\section{Authors' contributions}

SHA, M-CL, BHM and PS conceived, planned, and wrote this commentary. The authors read and approved the final manuscript.

\section{Funding}

SHA is supported by funding from the National Institutes of Mental Health, Canadian Institutes of Health Research (ClHR), and the Cundill Centre for Child and Youth Depression at the Centre for Addiction and Mental Health (CAMH). M-CL is supported by a CIHR Sex and Gender Science Chair, Women's Xchange, the Innovation Fund of the Alternative Funding Plan for the Academic Health Sciences Centres of Ontario, and the Ontario Brain Insti tute via the Province of Ontario Neurodevelopmental Disorders (POND) Network. M-CL and SHA are both supported by the O'Brien Scholars Program within the Child and Youth Mental Health Collaborative at CAMH and The Hospital for Sick Children, Toronto, the Academic Scholars Award from the Department of Psychiatry, University of Toronto, and the Slaight Family Child and Youth Mental Health Innovation Fund via the CAMH Foundation. BHM receives research support from Brain Canada, CIHR, the CAMH Foundation, the Patient-Centered Outcomes Research Institute (PCORI) and the US National Institutes of Health ( $\mathrm{NIH}$ ); during the past 3 years, he has received nonfinancial support from Eli Lilly (medications and matching placebo for a $\mathrm{NIH}$ funded clinical trial) and Pfizer (medications for a NIH-funded clinical trial), Capital Solution Design LLC (software used in a study funded by the CAMH Foundation), and HAPPYneuron (software used in a study founded by Brain Canada). PS is supported by the Patsy and Jamie Anderson Chair in Child and Youth Mental Health and CIHR; he receives royalties from Guilford Press and Simon \& Schuster. The funders have no role in the design of the study, the collection, analysis, and interpretation of data and writing of the manuscript.

\section{Availability of data and materials}

Not applicable

\section{Ethics approval and consent to participate}

Not applicable

\section{Consent for publication}

Not applicable

\section{Competing interests}

The authors declare that they have no competing interests.

\section{Author details}

${ }^{1}$ Centre for Addiction and Mental Health, 80 Workman Way, Toronto, ON M6J 1H4, Canada. 'Department of Psychiatry, The Hospital for Sick Children, Toronto, Canada. ${ }^{3}$ Department of Psychiatry, Faculty of Medicine, University of Toronto, Toronto, Canada. ${ }^{4}$ Autism Research Centre, Department of Psychiatry, University of Cambridge, Cambridge, UK. ${ }^{5}$ Department of Psychiatry, National Taiwan University Hospital and College of Medicine, Taipei, Taiwan
Received: 18 May 2020 Accepted: 15 July 2020

Published online: 22 July 2020

\section{References}

1. Lyall K, Croen L, Daniels J, Fallin MD, Ladd-Acosta C, Lee BK, Park BY, Snyder NW, Schendel D, Volk H, et al. The changing epidemiology of autism spectrum disorders. Annu Rev Public Health. 2017;38:81-102.

2. Lai MC, Kassee C, Besney R, Bonato S, Hull L, Mandy W, Szatmari P, Ameis $\mathrm{SH}$. Prevalence of co-occurring mental health diagnoses in the autism population: a systematic review and meta-analysis. Lancet Psychiatry. 2019; 6(10):819-29.

3. Muskens JB, Velders FP, Staal WG. Medical comorbidities in children and adolescents with autism spectrum disorders and attention deficit hyperactivity disorders: a systematic review. Eur Child Adolesc Psychiatry. 2017;26(9):1093-103.

4. Lai MC, Anagnostou E, Wiznitzer M, Allison C, Baron-Cohen S. Evidencebased support for autistic people across the lifespan: maximising potential, minimising barriers, and optimising the person-environment fit. Lancet Neurol. 2020;19(5):434-51.

5. Amaral DG, de Vries PJ. COVID-19 and autism research: perspectives from around the globe. Autism Res. 2020;13(6):844-69.

6. Turk MA, Landes SD, Formica MK, Goss KD. Intellectual and developmental disability and COVID-19 case-fatality trends: TriNetX analysis. Disabil Health J. 2020;100942.

7. Colizzi M, Sironi E, Antonini F, Ciceri ML, Bovo C, Zoccante L. Psychosocial and behavioral impact of COVID-19 in autism spectrum disorder: an online parent survey. Brain Sci. 2020:10(6).

8. Ersoy K, Altin B, Sarikaya BB, Özkardas OG. The comparison of impact of health anxiety on dispositional hope and psychological well-being of mothers who have children diagnosed with autism and mothers who have normal children, in Covid-19 pandemic. Sosyal Bilimler Araştırma Dergisi. 2020;9(2):117-26.

9. den Houting J: Stepping out of isolation: autistic people and COVID-19. Autism in Adulthood 2020, 2(2):103-105.

10. Pellicano E, Stears M. The hidden inequalities of COVID-19. Autism. 2020; 1362361320927590.

11. Eshraghi AA, Li C, Alessandri M, Messinger DS, Eshraghi RS, Mittal R, Armstrong FD. COVID-19: overcoming the challenges faced by individuals with autism and their families. Lancet Psychiatry. 2020;7(6):481-3.

12. Courtenay K, Perera B. COVID-19 and people with intellectual disability: impacts of a pandemic. Ir J Psychol Med. 2020:1-21.

13. Landes SD, Turk MA, Formica MK, McDonald KE, Stevens JD. COVID-19 outcomes among people with intellectual and developmental disability living in residential group homes in New York State. Disabil Health J. 2020; 100969.

14. Howlin P, Moss P. Adults with autism spectrum disorders. Can J Psychiatry. 2012;57(5):275-83.

15. McMichael TM, Currie DW, Clark S, Pogosjans S, Kay M, Schwartz NG, Lewis J, Baer A, Kawakami V, Lukoff MD, et al. Epidemiology of Covid-19 in a longterm care facility in King County. Washington. N Engl J Med. 2020;382(21): 2005-11.

16. Brown EE, Kumar S, Rajji TK, Pollock BG, Mulsant BH. Anticipating and mitigating the impact of the COVID-19 pandemic on alzheimer's disease and related dementias. Am J Geriatr Psychiatry. 2020;28(7):712-21.

17. Holmes EA, O'Connor RC, Perry VH, Tracey I, Wessely S, Arseneault L, Ballard C, Christensen H, Cohen Silver R, Everall I, et al. Multidisciplinary research priorities for the COVID-19 pandemic: a call for action for mental health science. Lancet Psychiatry. 2020;7(6):547-60.

18. Kissler SM, Tedijanto C, Goldstein E, Grad YH, Lipsitch M. Projecting the transmission dynamics of SARS-CoV-2 through the postpandemic period. Science. 2020;368(6493):860-8.

19. Crowell JA, Keluskar J, Gorecki A. Parenting behavior and the development of children with autism spectrum disorder. Compr Psychiatry. 2019;90:21-9.

20. Dykens EM, Fisher MH, Taylor JL, Lambert W, Miodrag N. Reducing distress in mothers of children with autism and other disabilities: a randomized trial. Pediatrics. 2014;134(2):e454-63.

21. Baribeau DA, Vigod S, Pullenayegum E, Kerns CM, Mirenda P, Smith IM, Vaillancourt T, Volden J, Waddell C, Zwaigenbaum L, et al. Repetitive behavior severity as an early indicator of risk for elevated anxiety symptoms in autism spectrum disorder. J Am Acad Child Adolesc Psychiatry. 2020:59(7): 890-9 e893. 
22. Curtin C, Hubbard K, Anderson SE, Mick E, Must A, Bandini LG. Food selectivity, mealtime behavior problems, spousal stress, and family food choices in children with and without autism spectrum disorder. J Autism Dev Disord. 2015:45(10):3308-15.

23. Must A, Eliasziw M, Phillips SM, Curtin C, Kral TV, Segal M, Sherwood NE, Sikich L, Stanish HI, Bandini LG. The effect of age on the prevalence of obesity among US youth with autism spectrum disorder. Child Obes. 2017; 13(1):25-35.

24. Grove R, Hoekstra RA, Wierda M, Begeer S. Special interests and subjective wellbeing in autistic adults. Autism Res. 2018;11(5):766-75.

25. Slobodin O, Heffler KF, Davidovitch M. Screen media and autism spectrum disorder: a systematic literature review. J Dev Behav Pediatr. 2019;40(4):303-11.

26. Boyd BA, McDonough SG, Bodfish JW. Evidence-based behavioral interventions for repetitive behaviors in autism. J Autism Dev Disord. 2012; 42(6):1236-48.

27. Schreck KA, Richdale AL. Sleep problems, behavior, and psychopathology in autism: inter-relationships across the lifespan. Curr Opin Psychol. 2019;34:105-11.

28. Fitzpatrick SE, Srivorakiat L, Wink LK, Pedapati EV, Erickson CA. Aggression in autism spectrum disorder: presentation and treatment options. Neuropsychiatr Dis Treat. 2016;12:1525-38.

29. Hill AP, Zuckerman KE, Hagen AD, Kriz DJ, Duvall SW, van Santen J, Nigg J, Fair D, Fombonne E. Aggressive behavior problems in children with autism spectrum disorders: prevalence and correlates in a large clinical Sample. Res Autism Spectr Disord. 2014;8(9):1121-33.

30. Keenan BM, Newman LK, Gray KM, Rinehart NJ. Parents of children with ASD experience more psychological distress, parenting stress, and attachment-related anxiety. J Autism Dev Disord. 2016;46(9):2979-91.

31. Golberstein E, Wen H, Miller BF. Coronavirus disease 2019 (COVID-19) and mental health for children and adolescents. JAMA Pediatr. 2020.

32. Holden R, Mueller J, McGowan J, Sanyal J, Kikoler M, Simonoff E, Velupillai S, Downs J. Investigating bullying as a predictor of suicidality in a clinical sample of adolescents with autism spectrum disorder. Autism Res. 2020; 13(6):988-97.

33. Forrest DL, Kroeger RA, Stroope S. Autism spectrum disorder symptoms and bullying victimization among children with autism in the United States. J Autism Dev Disord. 2020;50(2):560-71.

34. Hedley D, Uljarevic M, Wilmot M, Richdale A, Dissanayake C. Brief report: social support, depression and suicidal ideation in adults with autism spectrum disorder. J Autism Dev Disord. 2017;47(11):3669-77.

35. Shattuck PT, Orsmond Gl, Wagner M, Cooper BP. Participation in social activities among adolescents with an autism spectrum disorder. PLOS ONE. 2011;6(11):e27176.

36. Orben A, Tomova L, Blakemore SJ. The effects of social deprivation on adolescent development and mental health. Lancet Child Adolesc Health. 2020.

37. Johansson S, Gulliksen J, Gustavsson C. Disability digital divide: the use of the internet, smartphones, computers and tablets among people with disabilities in Sweden. Universal Access in the Information Society. 2020.

38. Barger B, Squires J, Greer M, Noyes-Grosser D, Eile JM, Rice C, Shaw E, Surprenant KS, Twombly E, London S, et al. State variability in diagnosed conditions for IDEA part C eligibility. Infants Young Child. 2019;32(4):231-44.

39. Cidav Z, Marcus SC, Mandell DS. Implications of childhood autism for parental employment and earnings. Pediatrics. 2012;129(4):617-23.

40. Dow D, Guthrie W, Stronach ST, Wetherby AM. Psychometric analysis of the Systematic Observation of Red Flags for autism spectrum disorder in toddlers. Autism. 2017;21(3):301-9.

41. Juarez AP, Weitlauf AS, Nicholson A, Pasternak A, Broderick N, Hine J, Stainbrook JA, Warren Z. Early identification of ASD through telemedicine: potential value for underserved populations. J Autism Dev Disord. 2018;48(8): 2601-10.

42. Dow D, Day TN, Kutta TJ, Nottke C, Wetherby AM. Screening for autism spectrum disorder in a naturalistic home setting using the systematic observation of red flags (SORF) at 18-24 months. Autism Res. 2020;13(1):122-33.

43. Houghton R, Liu C, Bolognani F. Psychiatric comorbidities and psychotropic medication use in autism: a matched cohort study with ADHD and general population comparator groups in the United Kingdom. Autism Res. 2018; 11(12):1690-700

44. Jobski K, Hofer J, Hoffmann F, Bachmann C. Use of psychotropic drugs in patients with autism spectrum disorders: a systematic review. Acta Psychiatr Scand. 2017;135(1):8-28.

45. McCracken JT. Safety issues with drug therapies for autism spectrum disorders. J Clin Psychiatry. 2005;66(Suppl 10):32-7.
46. Cortese $\mathrm{S}$, Asherson P, Sonuga-Barke E, Banaschewski T, Brandeis D, Buitelaar J, Coghill D, Daley D, Danckaerts M, Dittmann RW, et al. ADHD management during the COVID-19 pandemic: guidance from the European ADHD Guidelines Group. Lancet Child Adolesc Health. 2020;4(6):412-4.

47. Feder A, Fred-Torres S, Southwick SM, Charney DS. The biology of human resilience: opportunities for enhancing resilience across the life span. Biol Psychiatry. 2019;86(6):443-53.

48. Ungar M. Practitioner Review: Diagnosing childhood resilience--a systemic approach to the diagnosis of adaptation in adverse social and physical ecologies. J Child Psychol Psychiatry. 2015;56(1):4-17.

49. lacob Cl, Avram E, Cojocaru D, Podina IR. Resilience in familial caregivers of children with developmental disabilities: a meta-analysis. J Autism Dev Disord. 2020.

50. Bekhet AK, Johnson NL, Zauszniewski JA. Resilience in family members of persons with autism spectrum disorder: a review of the literature. Issues Ment Health Nurs. 2012;33(10):650-6.

51. Lai MC, Szatmari P. Resilience in autism: Research and practice prospects. Autism. 2019;23(3):539-41.

52. Pickles A, Anderson DK, Lord C. Heterogeneity and plasticity in the development of language: a 17-year follow-up of children referred early for possible autism. J Child Psychol Psychiatry. 2014;55(12):1354-62.

53. Salomone E, Beranova S, Bonnet-Brilhault F, Briciet Lauritsen M, Budisteanu M, Buitelaar J, Canal-Bedia R, Felhosi G, Fletcher-Watson S, Freitag C, et al. Use of early intervention for young children with autism spectrum disorder across Europe. Autism. 2016;20(2):233-49.

54. Liu G, Pearl AM, Kong L, Leslie DL, Murray MJ. A Profile on emergency department utilization in adolescents and young adults with autism spectrum disorders. J Autism Dev Disord. 2017;47(2):347-58.

55. Weiss JA, Isaacs B, Diepstra H, Wilton AS, Brown HK, McGarry C, Lunsky Y. Health concerns and health service utilization in a population cohort of young adults with autism spectrum disorder. J Autism Dev Disord. 2018; 48(1):36-44.

56. Frazier TW, Dawson G, Murray D, Shih A, Sachs JS, Geiger A. Brief report: a survey of autism research priorities across a diverse community of stakeholders. J Autism Dev Disord. 2018;48(11):3965-71.

57. Anderson C, Butt C. Young adults on the autism spectrum: the struggle for appropriate services. J Autism Dev Disord. 2018;48(11):3912-25.

58. Abrams J, Sossong S, Schwamm LH, Barsanti L, Carter M, Kling N, Kotarski M, Leddy J, Meller B, Simoni M, et al. Practical issues in delivery of clinician-topatient telemental health in an academic medical center. Harv Rev Psychiatry. 2017;25(3):135-45.

59. Bashshur RL, Shannon GW, Bashshur N, Yellowlees PM: The empirical evidence for telemedicine interventions in mental disorders. Telemed J E Health 2016, 22(2):87-113.

60. Stainbrook JA, Weitlauf AS, Juarez AP, Taylor JL, Hine J, Broderick N, Nicholson A, Warren Z. Measuring the service system impact of a novel telediagnostic service program for young children with autism spectrum disorder. Autism. 2019;23(4):1051-6.

61. Anderson DK, Liang JW, Lord C. Predicting young adult outcome among more and less cognitively able individuals with autism spectrum disorders. $J$ Child Psychol Psychiatry. 2014;55(5):485-94.

62. Nevill RE, Lecavalier L, Stratis EA. Meta-analysis of parent-mediated interventions for young children with autism spectrum disorder. Autism. 2018;22(2):84-98.

63. Parsons D, Cordier R, Vaz S, Lee HC. Parent-mediated intervention training delivered remotely for children with autism spectrum disorder living outside of urban areas: systematic review. J Med Internet Res. 2017;19(8):e198.

64. Lindgren S, Wacker D, Schieltz K, Suess A, Pelzel K, Kopelman T, Lee J, Romani $\mathrm{P}$, O'Brien M. A randomized controlled trial of functional communication training via telehealth for young children with autism spectrum disorder. J Autism Dev Disord. 2020.

65. Nicol GE, Piccirillo JF, Mulsant BH, Lenze EJ. Action at a Distance: Geriatric research during a pandemic. J Am Geriatr Soc. 2020;68(5):922-5.

66. Todorow C, Connell J, Turchi RM. The medical home for children with autism spectrum disorder: an essential element whose time has come. Curr Opin Pediatr. 2018;30(2):311-7.

67. Rast JE, Shattuck PT, Roux AM, Anderson KA, Kuo A. The medical home and health care transition for youth with autism. Pediatrics. 2018;141(Suppl 4): S328-34.

68. Cross SP, Hickie I. Transdiagnostic stepped care in mental health. Public Health Res Pract. 2017:27(2). 
69. Veinot TC, Mitchell H, Ancker JS. Good intentions are not enough: how informatics interventions can worsen inequality. J Am Med Inform Assoc. 2018;25(8):1080-8.

70. Crawford A, Serhal E. Digital Health Equity and COVID-19: The innovation curve cannot reinforce the social gradient of health. J Med Internet Res. 2020;22(6):e19361.

\section{Publisher's Note}

Springer Nature remains neutral with regard to jurisdictional claims in published maps and institutional affiliations.

- fast, convenient online submission

- thorough peer review by experienced researchers in your field

- rapid publication on acceptance

- support for research data, including large and complex data types

- gold Open Access which fosters wider collaboration and increased citations

- maximum visibility for your research: over $100 \mathrm{M}$ website views per year

At $\mathrm{BMC}$, research is always in progress. 